Article

\title{
Experimental Investigations on the Influence of Different Notch Designs on the Pullout Performance of Circumferentially Notched Z-Pins
}

\author{
André Knopp * (D) and Gerhard Scharr \\ Chair of Lightweight Design and Materials, Department of Mechanical Engineering and Marine Technology, \\ University of Rostock, Albert-Einstein-Str. 2, 18059 Rostock, Germany; gerhard.scharr@uni-rostock.de \\ * Correspondence: andre.knopp@uni-rostock.de; Tel.: +49-381-498-9294
}

Received: 7 May 2020; Accepted: 2 June 2020; Published: 5 June 2020

\begin{abstract}
The results of experimental research on the pullout properties of circumferentially notched z-pins with various notch designs are presented in this paper. Investigations on notched z-pins with four different notch designs—rectangular, circular, triangular, and sinusoidal-inserted into unidirectional (UD) and quasi-isotropic (QI) laminates were carried out in order to assess the influence of notch design and laminate structure on the resulting z-pin pullout properties. It can be shown that the application of circumferential notches at the z-pin surface causes significant increases in pullout forces and consequently, on the resulting pullout energies, regardless of which notch design is considered. The effect of notched z-pins is higher in a quasi-isotropic than in a unidirectional laminate structure. The highest enhancements of the pullout energy were found on quasi-isotropic laminates with circular and sinusoidal notch designs with increases of up to $69 \%$, in comparison to measurements on samples with unnotched z-pins.
\end{abstract}

Keywords: 3-dimensional reinforcement; bridging mechanisms; circumferentially notched; pullout energy; z-pinning

\section{Introduction}

In the last few decades, the importance of composite materials has increased steadily. Due to their excellent mechanical properties in combination with their low weight, carbon-fiber reinforced plastics (CFRP) are increasingly used in structural components for both aerospace applications as well as in new applications for electric mobility. The fracture-mechanical properties are crucial, since inhomogeneous cracks and materials of various sizes are always present in any composite structure. Under dynamic loads, they may grow and cause an increasing weakness of the composite structure. In addition, impact damage events can cause a significant reduction in the strength and stiffness properties of structural components made of fiber-reinforced plastics. These events may lead to delamination, which in turn leads to lower residual load capacities. There have been many developments on how to manage such cracks. Apart from the insertion of elastomer or thermoplastic particles into the primarily used thermosetting matrices [1,2], methods for the realization of three-dimensional fiber reinforcement structures exist, which can impede and indeed completely stop crack growth. Depending on the area of application, various textile techniques can be applied, such as 3D weaving [3-5], braiding [3,4,6,7], through-thickness stitching [4,8,9], or special techniques like tufting $[10,11]$ or $z$-Anchoring $[12,13]$ to create a 3D reinforcement structure and to achieve damage tolerant structural components with a desired safe life while maintaining specific performance at acceptable costs. When using preimpregnated semifinished fiber products (prepreg), the z-pin process is the preferred method for implementing a 3D fiber reinforcement due to the processing properties of 
these materials [14]. Numerous studies show that the insertion of a z-pin reinforcement has positive impacts on the delamination resistance of prepreg laminates. In general, an improvement of the delamination properties can be achieved under Mode-I [15-21], Mode-II [17,18,20-23], and mixed mode I/II stress [24-26] by the insertion of a z-pin reinforcement. Based on these properties, it can be stated that the impact damage resistance as well as the damage tolerance of a pinned laminate can be improved [27-29]. The inserted pins cause bridging effects at a crack under crack-opening loads, reducing the resulting stresses at the crack tip $[30,31]$. It involves energy dissipating mechanisms that can be described by the pullout process of the pins [20]. This results in a significant improvement of the interlaminar fracture toughness [23,32]. The interactions between z-pins and laminate during the z-pin-pullout process can be defined by the characteristic load-displacement curves, as illustrated by Figure 1.

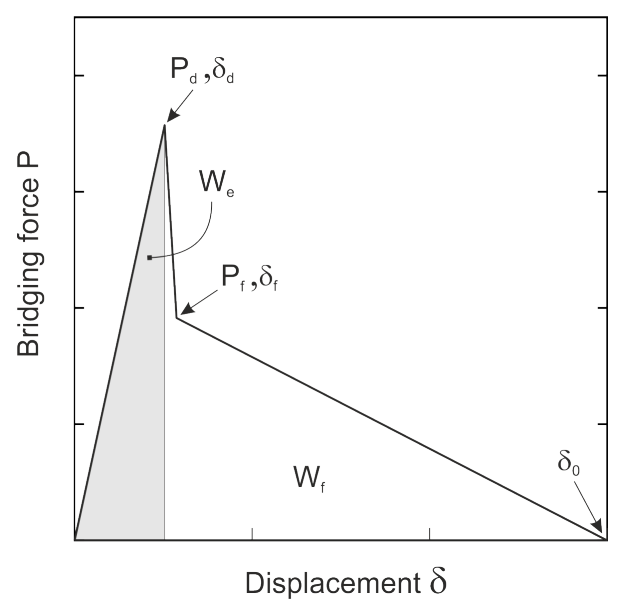

Figure 1. Characteristic trilinear load-displacement relationship during z-pin pullout loading.

The typical trilinear curves can be defined by the values-maximum debonding force $P_{d}$, maximum frictional force $P_{f}$, and their respective crack-opening displacements $\delta_{d}$ and $\delta_{f}$. The maximum crack-opening displacement value $\delta_{0}$ is reached once all pins are pulled out completely. The energy $W$ dissipated during the z-pin pullout can also be determined on the basis of the curve progressions. It consists of an elastic component $\mathrm{W}_{\mathrm{e}}$, which is primarily dependent on the adhesion between reinforcing elements and laminate; and a friction-induced part $W_{f}$, which is defined by the friction properties during the pullout process after complete debonding of the pins. The energy $\mathrm{W}$ dissipated during the pullout indicates the effectiveness of the z-pins to bridge the applied loads. Various investigations have been carried out to increase the transferable loads by means of suitable chemical, physical, or geometrical modifications of the z-pins, thus further increasing the delamination properties of the z-pinned laminates. Recent research shows that cryogenic and plasma surface treatment processes of the z-pin surface before insertion into the laminate can increase the surface roughness as well as cause active chemical groups which lead to an increased wettability with the matrix material and promote the formation of covalent bonds between matrix and pin surface. A surface treatment with liquid nitrogen and oxygen plasma leads to an increase of the pin-pullout energy $W$ of $52 \%$ and $114 \%$ respectively [33-35]. Wang et al. [36] used z-pins coated with c-fibers and carbon nanotubes to improve the z-pin pullout bridging forces by enhancing the interlocking effects. As a result, increases in z-pin laminate shear strength of up to $43 \%$ were achieved, causing an increase in pullout energy of $160 \%$. Vazquez et al. [37] reported improvements in pullout properties when the CFRP pins are formed by slightly twisted carbon-fiber tows and the matrix material of the pins was not fully cured (about $80 \%$ ) before insertion into the prepreg laminate. The improvements can be explained on the one hand by the improved adhesion properties between the pins and the laminate matrix, as the formation of covalent bonds between pin-surface and laminate matrix is promoted. On the other hand, the twisted structure enlarges the pin surface that can be wetted by the laminate matrix. 
Additionally, Wang et al. [38] achieved improvements of the pullout properties with twisted pins, which can be characterized by a tripling of the maximum frictional force as well as pullout energy and an increase of the maximum interfacial shear strength between z-pin and laminate of $61 \%$, compared to smooth pins. The investigations of Zhang et al. [39] performed on twisted pins indicate that increases in the maximum debonding and frictional force of up to $19.4 \%$ could be reached, due to the larger surface area with higher roughness caused by the twists. An enlarged surface area and improved interlocking effects between the z-pin surface and the laminate were found by Virakthi et al. [40] to be responsible for the significant increases in pullout strength values achieved in their investigations with threaded steel pins. Compared to the nonthreaded pins, it was possible to increase pullout strength by a factor of 3.5. Increased interlocking effects between z-pins and laminate can also be obtained by introducing circumferential notches at the z-pin surface. Hoffmann et al. [41] conducted investigations on circumferentially notched z-pins with rectangular notch design and notch depths between $25 \mu \mathrm{m}$ and $72 \mu \mathrm{m}$ and observed increases in the resulting pullout energy of up to $12 \%$, compared to the unnotched z-pins, for a unidirectional laminate structure and a notch depth of $25 \mu \mathrm{m}$.

On this basis, the present study carried out experimental investigations on the effect of the notch design on the z-pin pullout properties of microstructured z-pins with circumferential notches. Until now, only pullout tests have been performed on circumferentially notched z-pins with a rectangular cross-sectional geometry with notch depths between $25 \mu \mathrm{m}$ and $72 \mu \mathrm{m}$ [41]. It was shown that by microstructuring of the z-pin surface, the characteristic pullout forces and pullout energies could be increased significantly. During the application of rectangular notches at the z-pin surface, the unidirectional fibers of the pins are considerably damaged. Additionally, the notches cause stress concentrations under mechanical loading that can result in a reduction of the fracture performance of the pinned laminate. Consequently, the influence of the notch design on the pullout performance of circumferentially notched z-pins will be investigated. From the previous experimental results for rectangular notch designs, it can also be concluded that a further increase in pullout energy can be expected with reducing the notch depth to values less than $25 \mu \mathrm{m}$. The investigations should contribute to the determination of an optimal notch geometry.

\section{Materials and Test Procedure}

\subsection{Materials}

The pullout test specimens were made from a carbon-fiber prepreg tape supplied by Cytec Engineered Materials. The prepreg material has a unidirectional fiber orientation of IM7 (intermediate modulus) carbon fibers with a weight-per-unit area of $145 \mathrm{~g} / \mathrm{m}^{2}$. The matrix material is a toughened hot-curing epoxy resin system Cycom 977-2 with a curing temperature of $180^{\circ} \mathrm{C}$. The single-layer thickness in cured condition amounts to about $0.14 \mathrm{~mm}$. The three-dimensional reinforcement consists of thin, rod-shaped elements (pins) made of a fiber-reinforced plastic with a diameter of $0.5 \mathrm{~mm}$. Z-pins with a diameter of $0.5 \mathrm{~mm}$ are usually described as big pins. The impact on the resulting microstructure of the z-pinned laminate and therefore on the mechanical properties-e.g., the reduction of the in-plane properties-is higher than for pins with a small diameter $(0.28 \mathrm{~mm})$. However, pins with a diameter of $0.5 \mathrm{~mm}$ were used for the investigations carried out, as manual handling of these pins during the process of introducing notches is more convenient. Perspectively, z-pins smaller than $0.5 \mathrm{~mm}$ diameter should be used for the 3D-reinforcement. Hence, an automated process for the insertion of notches at the z-pin surface should be developed and implemented. The z-pins are made of a thermally stable bismaleimide (BMI) resin combined with unidirectional T300 carbon fibers. To determine the influence of notches on the pin pullout properties, circumferential notches with different cross-sectional shapes are added to a defined area at the surface of the z-pin by treatment with ultra-short laser pulses. The position of the notched area together with the detailed definition of the cross-sectional shapes of the different notch designs are shown in Figure 2. 
(a)

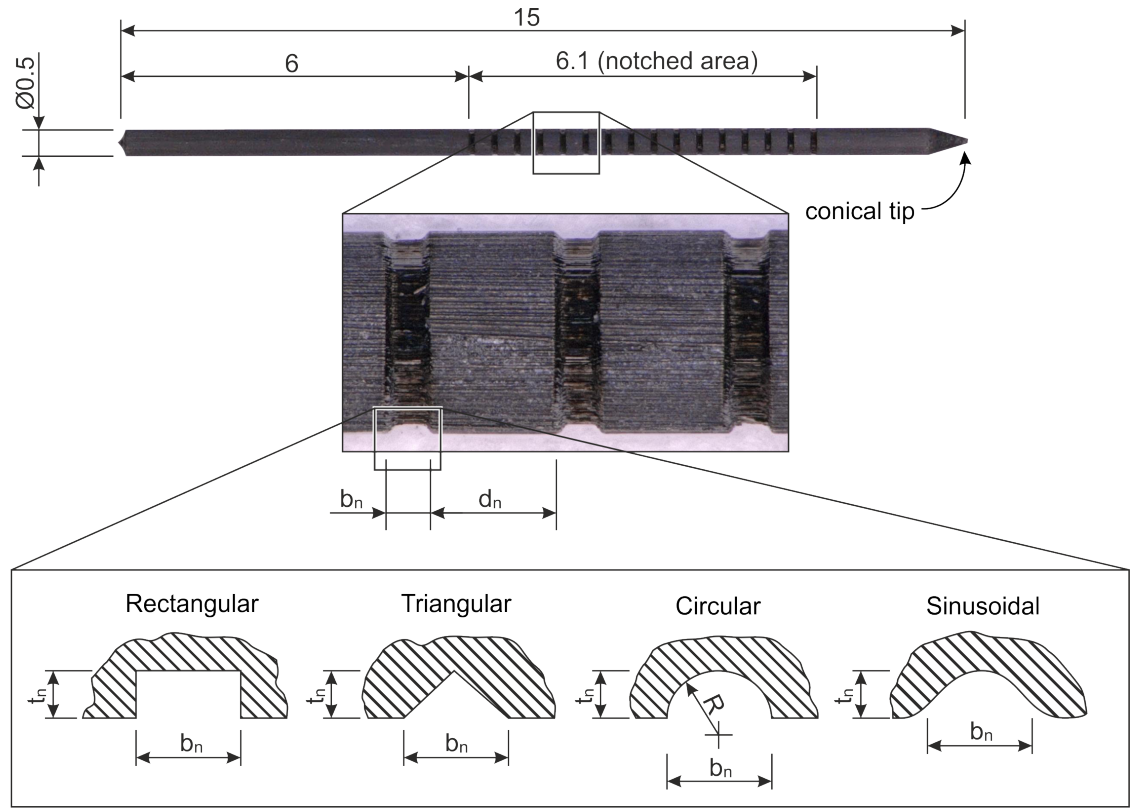

Figure 2. Definition of circumferential notches at the z-pin surface: (a) position and length of notched area at the z-pin surface, (b) definition of notch geometry, (c) different notch designs evaluated.

The notch area at the pin surface has a length of $6.1 \mathrm{~mm}$ to ensure that the notched section is positioned over the entire thickness of the laminate after insertion. Four different notch designs are examined-rectangular, triangular, circular, and sinusoidal. The width of the notches $b_{n}$ as well as the distance $d_{n}$ is $100 \mu \mathrm{m}$ for all notch definitions tested. An overview of the notch designs and definitions examined is summarized in Table 1.

Table 1. Details of investigated notch designs.

\begin{tabular}{|c|c|c|c|c|}
\hline \multicolumn{5}{|c|}{ Notch Definition } \\
\hline Design & $\begin{array}{c}\text { Depth } t_{n} \\
{[\mu \mathrm{m}]}\end{array}$ & $\begin{array}{l}\text { Width } b_{n} \\
{[\mu \mathrm{m}]}\end{array}$ & $\begin{array}{c}\text { Distance } d_{n} \\
{[\mu \mathrm{m}]}\end{array}$ & $\begin{array}{c}\text { No. of Specimens } \\
{[\text { Pcs }]}\end{array}$ \\
\hline Unnotched & - & - & - & 6 \\
\hline Rectangular & 20 & 100 & 100 & 6 \\
\hline Triangular & 20 & 100 & 100 & 6 \\
\hline Sinusoidal & 20 & 100 & 100 & 6 \\
\hline Circular & 20 & 100 & 100 & 6 \\
\hline Circular & 10 & 100 & 100 & 6 \\
\hline Circular & 15 & 100 & 100 & 6 \\
\hline Circular & 25 & 100 & 100 & 6 \\
\hline
\end{tabular}

Along with the test specimens with unnotched z-pins, investigations are carried out on specimens with notched pins with different notch designs while keeping the notch depth $t_{n}$ constant at $20 \mu \mathrm{m}$. Furthermore, for samples with circular notch design, investigations on different notch depths $t_{n}$ are carried out to determine the dependence of the pullout properties from the notch depth. For inserting the z-pins into the laminate, the Ultrasonically Assisted Z-Fibre process ${ }^{\mathrm{TM}}\left(\mathrm{UAZ}{ }^{\mathbb{R}}\right)$ is used. Freitas et al. [15,42] as well as Partridge et al. [29] give a comprehensive overview about the UAZ-process, which is used to insert thin, rod-shaped elements (pins) into the prepreg stack before curing cycle. The z-pins are inserted into a foam carrier in the desired configuration and driven into the laminate under axial pressure using an ultrasonic device. Once the notched areas on the pin surface are positioned in the laminate, the insertion process is completed and the parts of the pins that are protruding from the laminate are sheared off. Subsequently, the pinned laminate can be subjected to 
the curing process in an autoclave under material-specific curing conditions (pressure of $600-700 \mathrm{kPa}$ and a temperature of $180^{\circ} \mathrm{C}$ for $180 \mathrm{~min}$ ).

\subsection{Specimen Preparation and Pullout Test Set-Up}

Pullout studies were conducted to characterize the resulting bridging traction properties of unnotched and circumferentially notched z-pins with different notch definitions. The z-pin pullout test set-up used is shown in Figure 3.

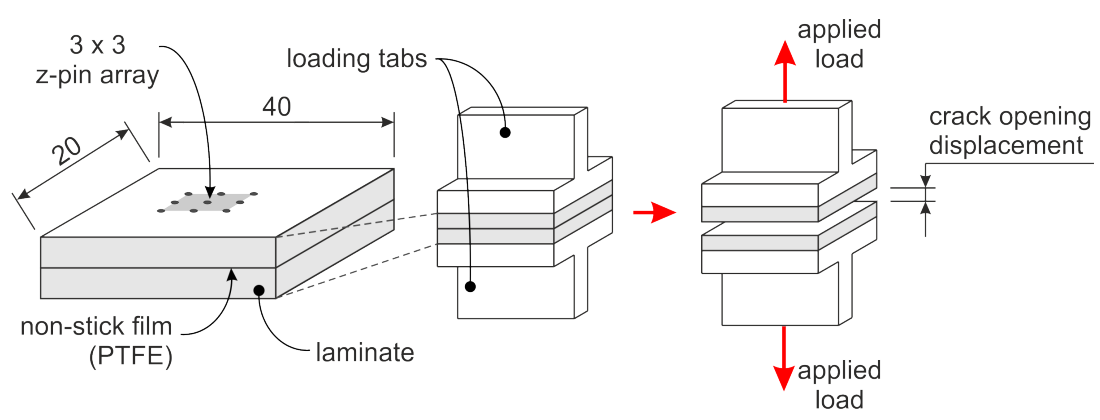

Figure 3. Definition of the z-pin pullout test sample geometry and test set-up.

The investigated laminates are made of 32 layers of prepreg tape in order to achieve a laminate thickness of around $4.5 \mathrm{~mm}$ after curing. Unidirectional (UD) $\left[0_{32}\right]$ laminates as well as quasi-isotropic (QI) $[ \pm 45 / 0 / 90]_{4 S}$ laminates are built up to determine the pullout properties of z-pin-reinforced laminates depending on the laminate structure. To apply pure pullout loads to the inserted z-pins, a nonstick polytetrafluoroethylene (PTFE) film with a thickness of $12.5 \mu \mathrm{m}$ is located in the midplane of the laminate. In the central region of the specimens, an area of $10 \mathrm{~mm} \times 10 \mathrm{~mm}$ is reinforced by unnotched or circumferentially notched z-pins. With a pin density of $1 \%$ for all specimens and a diameter of the used z-pins of $0.5 \mathrm{~mm}$, the z-pin array is $3 \times 3 \mathrm{z}$-pins. After the curing process and cutting the specimens from the laminate plate, T-shaped loading tabs were attached to the lower and upper side of the specimens for applying the crack-opening loads with a universal testing machine MTS-858 with a load-cell capacity of $2 \mathrm{kN}$. For each z-pin variant, six specimens were tested, as specified in Table 1. To determine the z-pin pullout properties, the specimens are loaded with a constant crack-opening displacement rate of $1 \mathrm{~mm} / \mathrm{min}$ and the load-displacement curves are recorded. The tests were conducted until all pins were pulled out completely or had failed. From the load-displacement curves, the relevant pullout parameters for a comparison of the test samples with unnotched z-pins as well as with circumferentially notched z-pins can be identified, such as the maximum debonding force $\mathrm{P}_{\mathrm{d}}$ and maximum frictional force $\mathrm{P}_{\mathrm{f}}$ as well as their respective displacement values. Furthermore, the energies-elastic pullout energy $W_{\mathrm{e}}$, frictional pullout energy $W_{\mathrm{f}}$, and total pullout energy $\mathrm{W}$-dissipated during the z-pin pullout process can be determined from the curve progressions. These values can be used to compare the different notch geometries to identify the notch definition having the greatest influence on the bridging effects.

\section{Results and Discussion}

\subsection{Pullout-Forces}

From the measured pullout curves, exemplified in Figure 4, for z-pinned samples with unnotched z-pins as well as triangular and sinusoidal circumferentially notched z-pins, the characteristic force values-maximum debonding force $\mathrm{P}_{\mathrm{d}}$ as well as maximum frictional force $\mathrm{P}_{\mathrm{f}}$ - can be determined. 


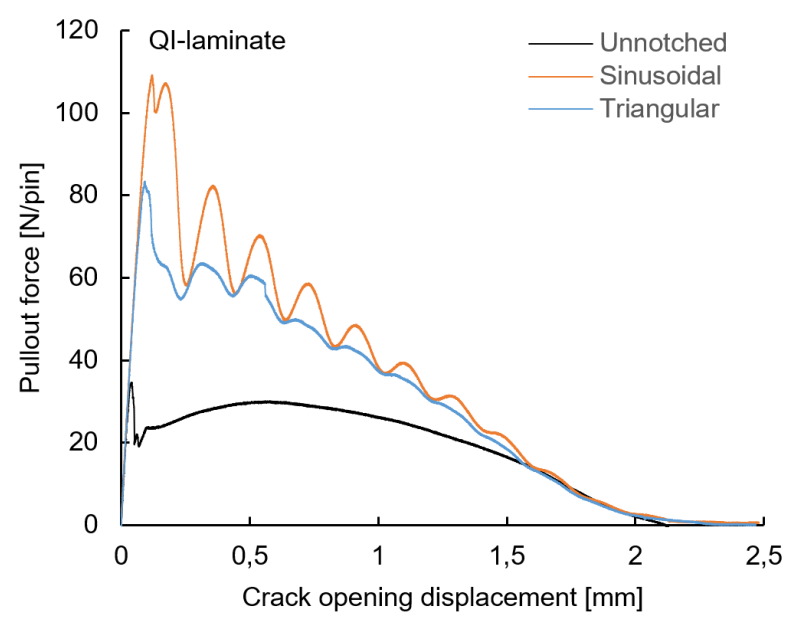

Figure 4. Representative z-pin pullout curves of unnotched and circumferentially notched z-pins with different notch designs in quasi-isotropic laminates.

It can be seen from the figure that the maximum values for $\mathrm{P}_{\mathrm{d}}$-i.e., the force required to detach a pin from the laminate-can be significantly increased by the application of notches at the z-pin surface, regardless of the notch geometry. This also applies to the values of the maximum frictional force $P_{f}$, which indicate the impact of the friction between pins and laminate during the pullout. It also increases with the presence of a notched structure on the z-pin surface, compared to the measured values of the sample with unnotched z-pins. A comparison of the values for the different notch designs with those of the unnotched pins gives an indication of the effectiveness of such a surface texturing. Figure 5 summarizes the mean values of the debonding and frictional forces as well as the corresponding standard deviation values for samples with unnotched and circumferentially notched pins with different notch designs in unidirectional and quasi-isotropic laminate structures.

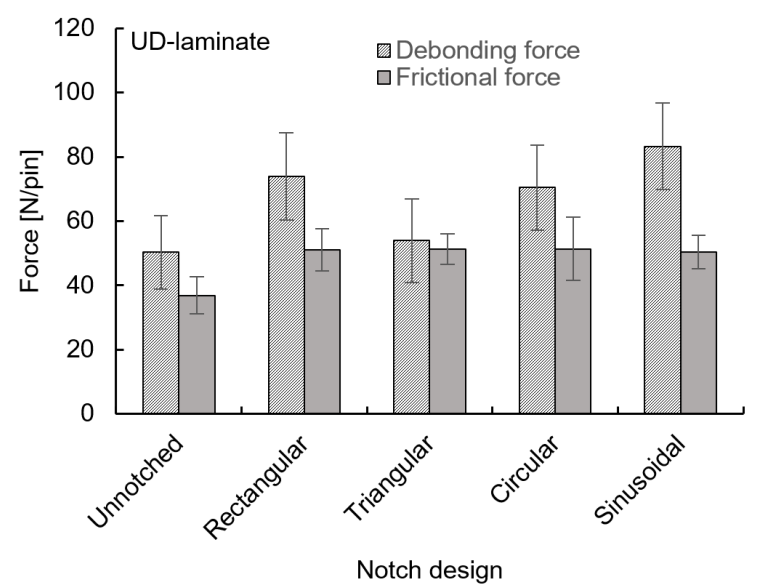

(a)

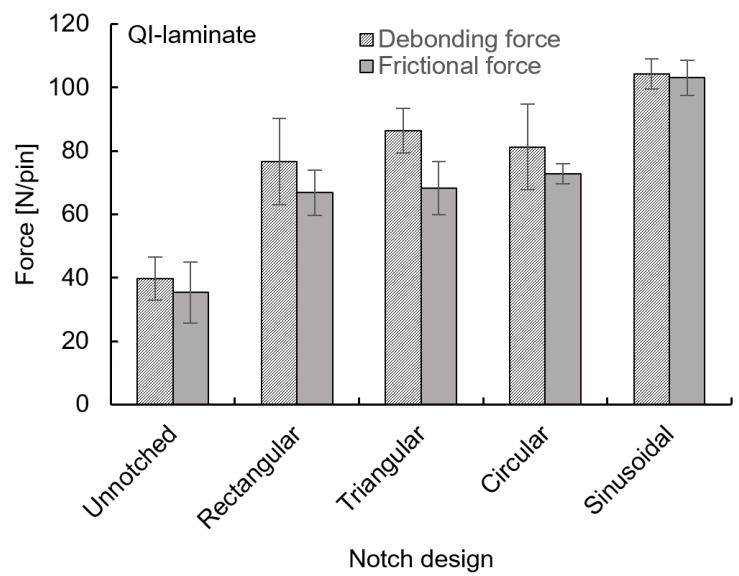

(b)

Figure 5. Mean values and corresponding standard deviation values of debonding and frictional forces during pin-pullout of unnotched and circumferentially notched z-pins with different notch designs and constant notch depths of $20 \mu \mathrm{m}$ as well as notch distances of $100 \mu \mathrm{m}$ in a (a) unidirectional and (b) quasi-isotropic laminate structure.

For unidirectional laminates, as shown in Figure 5a, significant enhancements can be obtained for both debonding and frictional forces by using notched pins. The improvements of the debonding force range between $7 \%$ and $66 \%$ with respect to the unnotched samples with the highest values for sinusoidal notches. The frictional force also substantially increases passing from the unnotched to notched pins. However, no significant differences in the frictional force values of the various notch 
designs can be observed. All notch designs examined were found to have an increase in frictional force ranging from $37 \%$ to $39 \%$. With a quasi-isotropic laminate structure, as primarily used in technical applications, substantial improvements of $P_{d}$ and $P_{f}$ can be detected when using notched z-pins. Figure $5 \mathrm{~b}$ shows the results of the investigations on quasi-isotropic laminate structures. The debonding force values show an increase between $93 \%$ and $162 \%$, whereas the sinusoidal notch design also gives the best results. The frictional forces follow the previously explained values of the debonding forces and increase from $89 \%$ to $191 \%$. The sinusoidal notch design was the best overall. On the one hand, the geometrical characteristics of a sinusoidal notch geometry may help to explain why the debonding forces are largest. Assuming a constant position of the shear area (radius of the sheared pin) for the different notch geometries, a sinusoidal notch geometry will result in a larger shearing surface running through the web areas of the notched region of the pins. Thus, higher forces are required to detach the notched pins with sinusoidal notch geometry from the laminate and consequently, a higher elastic pullout energy can be expected. On the other hand, due to the continuous transition between webs and notches, less-intense stress concentrations, which can lead to premature failure in the transition areas, can be expected compared with the other notch types. If higher values for the maximum debonding force $P_{d}$ are achieved by introducing notch structures at the z-pin surface than for unnotched pins, it can be deduced that the z-pins have better bonding or anchoring in the laminate due to the notch structures. Consequently, the increases in debonding force should be directly reflected in the values of the elastic pullout energy, since higher energies are necessary to separate the pins from the laminate. This has already been demonstrated by Knopp et al. [33,34] on pins previously subjected to a surface treatment using liquid nitrogen and different plasmas. Especially with the findings on cryogenically treated pins, it can be assumed that the increases in debonding and frictional properties are mainly driven by the enhanced surface roughness and the resulting interlocking effects. The higher values of the frictional force $P_{\mathrm{f}}$ indicate higher frictional interaction between the surfaces of the pins and the surrounding laminate. The reason can be found in the resulting microstructure at z-pin/laminate interface, as shown in Figure 6, for a partially pulled-out notched z-pin with sinusoidal notch design.

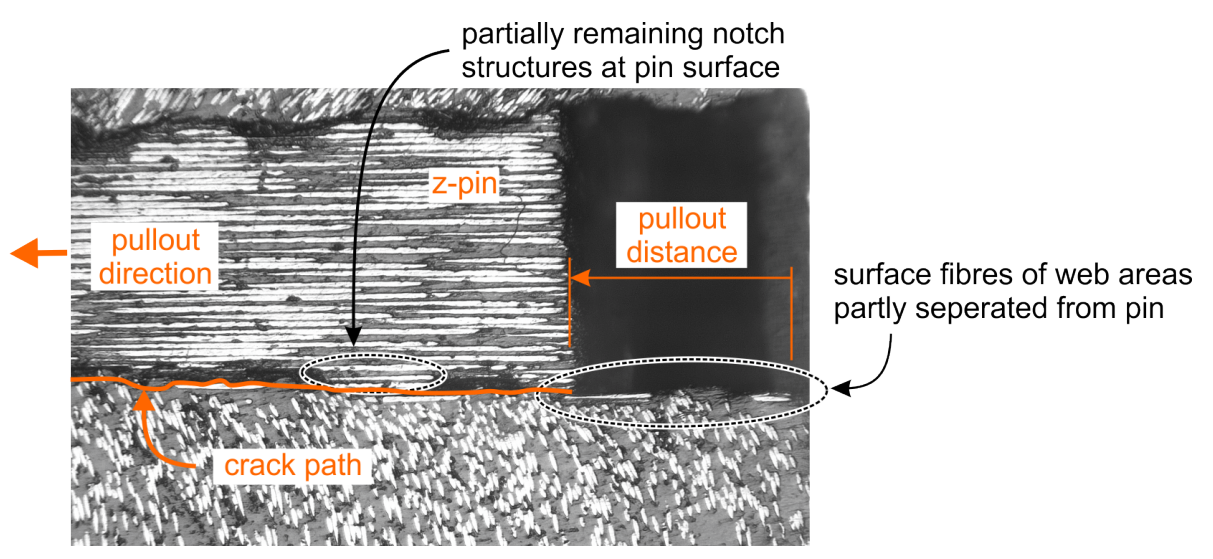

Figure 6. Partially pulled-out pin with circumferential notches with sinusoidal notch design; crack path is marked and remaining notch structure can be observed at z-pin surface and in the laminate.

The pathway of the crack between z-pins and laminate is marked in color for better visibility. It can be observed that surface fibers of the pin are detached from the web areas between the notches so that the positions of the notches before pullout forces were applied are still discernible. The sheared fibers are still adhered to the laminate structure. During z-pin pullout, these fibers cause interlocking effects with the fibers in the web areas at the z-pin surface, resulting in higher resistance against the pullout. During the z-pin pullout, these areas are frequently superimposed which leads to the wavelike force-displacement curve progression, as exemplarily shown in Figure 4. The influence of the surface roughness in the area of the notches, resulting from the treatment process using ultra-short laser pulses, was not considered in the investigations carried out. In order to overcome the higher forces, a rise 
in the required energy-the friction pullout energy $W_{\mathrm{f}}-$ can also be expected. The investigations on different notch depths using circular notch designs with a constant notch distance of $100 \mu \mathrm{m}$ for unidirectional and quasi-isotropic laminate structures are shown in Figure 7.

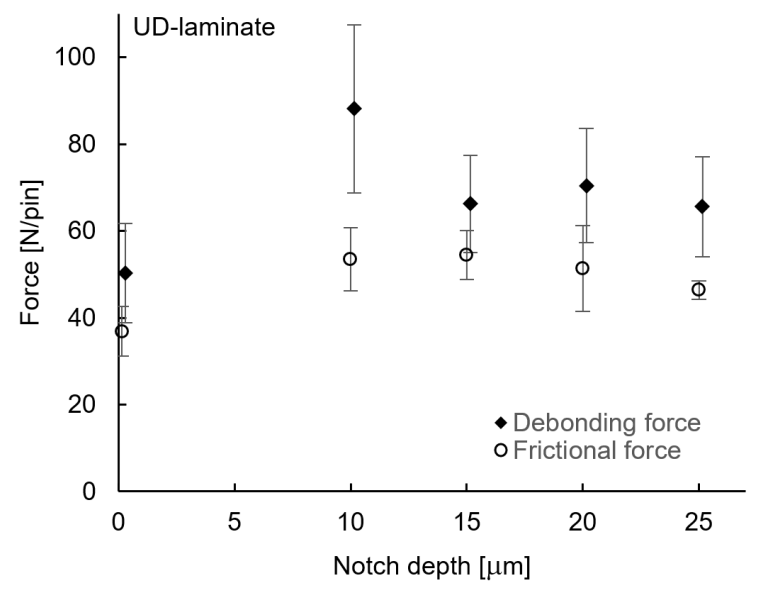

(a)

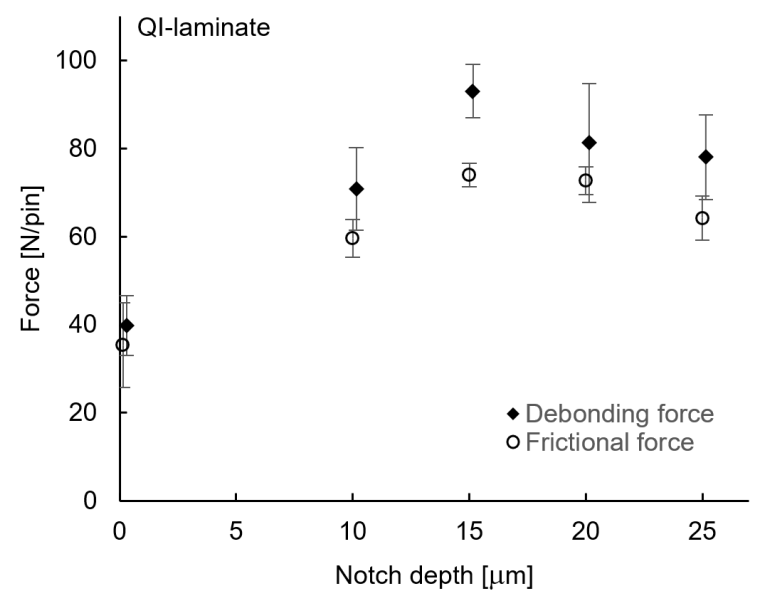

(b)

Figure 7. Mean values and corresponding standard deviation values of debonding and frictional forces measured during z-pin pullout of unnotched and circumferentially notched z-pins with circular notch design and different notch depths in (a) unidirectional and (b) quasi-isotropic laminate structures.

Figure 7a represents the influence of the notch depth for circular notch designs on the characteristic force values $\mathrm{P}_{\mathrm{d}}$ and $\mathrm{P}_{\mathrm{f}}$ for a unidirectional laminate structure. For the examined notch depths, an increase in the force values can be observed by reducing the notch depth. Both force values have their maximum at a notch depth of $10 \mu \mathrm{m}$ and show improvements of about $75 \%$ for $\mathrm{P}_{\mathrm{d}}$ and $45 \%$ for $\mathrm{P}_{\mathrm{f}}$ compared to the unnotched pins. The results for the quasi-isotropic laminates (see Figure $7 \mathrm{~b}$ ) show similar characteristics, however, the respective increases are higher-134\% for $P_{d}$ and $109 \%$ for $\mathrm{P}_{\mathrm{f}}$-and reach their maximum at a notch depth of about $15 \mu \mathrm{m}$.

\subsection{Z-Pin Traction Energy}

To evaluate the effectiveness of a z-pin reinforcement, it is necessary to know the energy dissipated during the z-pin pullout process. The elastic pullout energy $W_{\mathrm{e}}$, which corresponds to the energy dissipated during the pullout until the pins are completely detached from the laminate; combined with the frictional part $W_{\mathrm{f}}$, which represents the energy dissipated starting when the pins are completely detached until the pullout is completed, equals the total pullout energy $W$. By comparing these parameters for the investigated notch designs and laminate structures, it is possible to identify the notch design that has the greatest impact on the fracture-mechanical and impact properties of the pinned laminate. Furthermore, the sensitivity of the abovementioned properties to notch geometry can be assessed. In Figure 8, average values and corresponding standard deviation of the elastic (a), frictional (b), and total (c) pullout energies are shown for the various notch designs in unidirectional and quasi-isotropic laminate structures. 


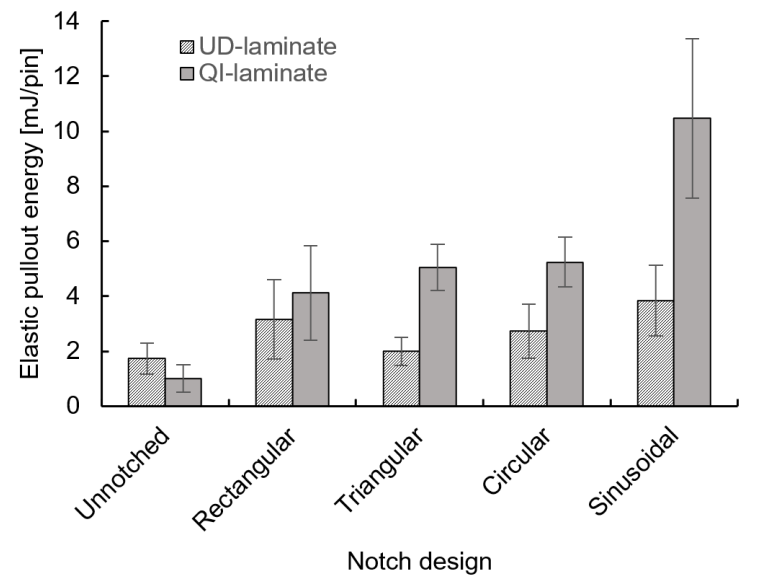

(a)

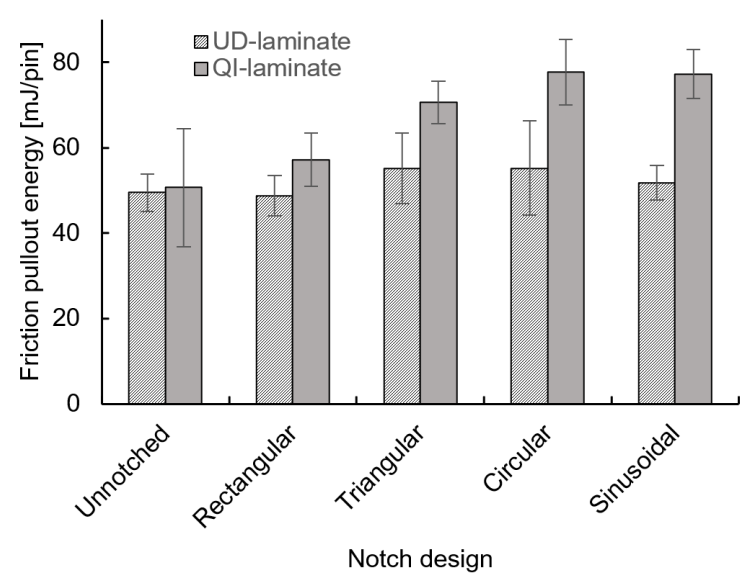

(b)

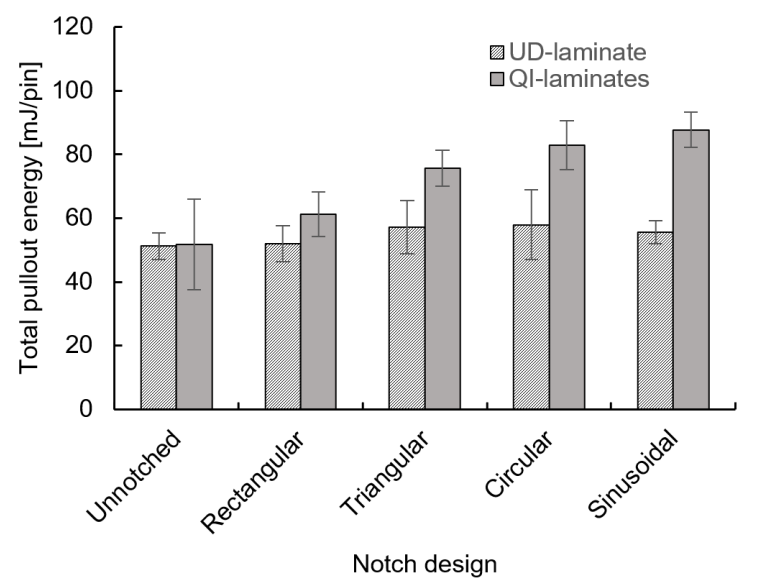

(c)

Figure 8. Mean values and corresponding standard deviation of elastic (a), frictional (b), and total (c) pullout energy dissipated during z-pin pullout of unnotched and circumferentially notched z-pins with different notch designs in unidirectional and quasi-isotropic laminates.

The elastic values of the pullout energy indicate that by applying notches at the pin surfaces, higher values can be achieved, regardless of the notch geometry and laminate structure. For a unidirectional laminate structure, increases of up to $123 \%$ can be realized with sinusoidal notch designs. The triangular shape provides the lowest increases of around $15 \%$ compared to the unnotched pins. The values obtained directly follow the debonding forces of the respective notch design. In a quasi-isotropic laminate structure, the test specimens with a sinusoidal notch design also show the highest values, which corresponds to a rise of the elastic pullout energy of $947 \%$. This implies that the energy required to debond the notched pins with sinusoidal notches from the laminate under axial loading is approximately 10 times higher than for the unnotched z-pins. If the energy introduced into the material is high enough to detach the pins, then higher friction values during pin pullout effectively impede crack growth by reducing the energy at the crack tip as a result of the bridging effect [14]. The determined frictional pullout energies for the various notch designs are shown in Figure 8 b. The frictional energy $W_{f}$, which represents the bigger part of the total energy $W$, shows only small enhancements up to a maximum of $12 \%$ for triangular and circular notch designs for unidirectional laminates. By contrast, no increase can be shown for a rectangular notch design. The pins with sinusoidal notches also show only minor increases of $\mathrm{W}_{\mathrm{f}}$ of about $5 \%$. In comparison, for quasi-isotropic laminate structures, the improvements are higher than those for samples with UD laminate structures. Improvements in friction energy of up to $53 \%$ can be measured for both circular 
and sinusoidal notch designs. The rectangular notch design also provides the lowest values with an increase of $13 \%$. Once again, these results are consistent with the data gathered for the maximum frictional pullout force $P_{\mathrm{f}}$ (see Figure 6). To determine the total pullout energy, the elastic values and frictional values are combined. The results are presented in Figure $8 \mathrm{c}$ for unidirectional and quasi-isotropic laminates. It can be seen that at a notch depth of $20 \mu \mathrm{m}$, a notch distance of $100 \mu \mathrm{m}$, and a notch width of also $100 \mu \mathrm{m}$ for unidirectional laminate structures, the triangular notches as well as the circular notches have the largest increase with respect to the unnotched pins of $12-13 \%$. By contrast, rectangular notches show no significant improvement in total pullout energy. The improvements achieved for QI laminates are greater and become maximum for circular and sinusoidal notch designs. This means that enhancements in pullout energy of up to $69 \%$ can be recorded.

If only the pullout energies for specimens with circular notch designs and different notch depths are considered, as illustrated in Figure 9, for the elastic portion (a), the frictional portion (b), and the total energy $(\mathrm{c})$, the values of the elastic energies $W_{\mathrm{e}}$ and frictional pullout energies $\mathrm{W}_{\mathrm{f}}$ are also following the values described above for the debonding and frictional forces.

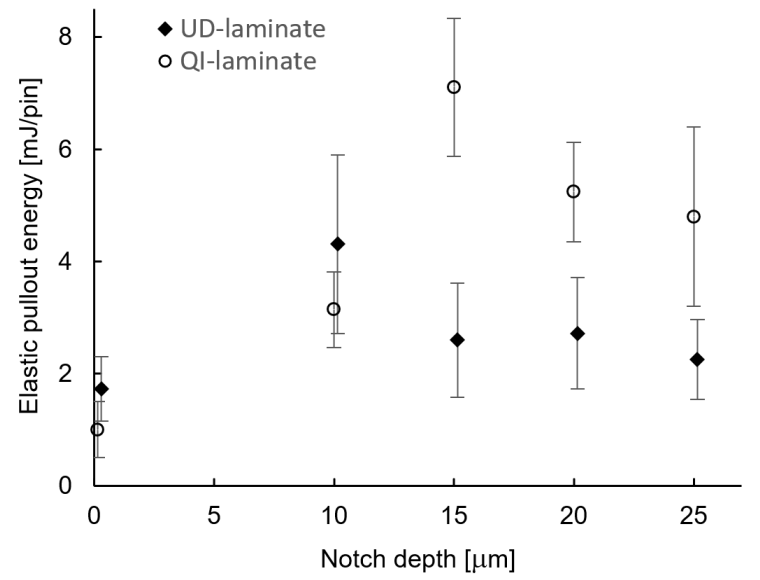

(a)

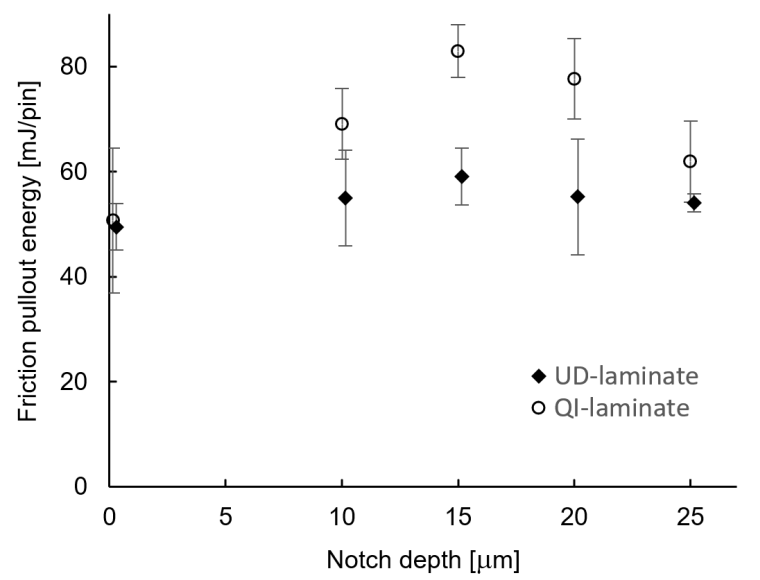

(b)

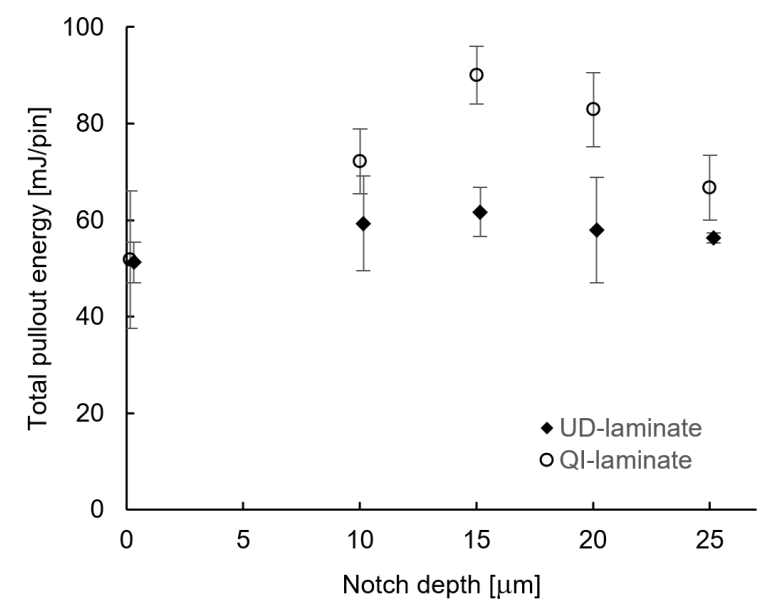

(c)

Figure 9. Mean values and corresponding standard deviation of elastic (a), friction (b), and total (c) pullout energy dissipated during z-pin pullout of unnotched and circumferentially notched z-pins with circular notch design and different notch depths in unidirectional and quasi-isotropic laminates.

For unidirectional laminate structures, the maximum energy values are found for $\mathrm{W}_{\mathrm{e}}$ at a notch depth of $10 \mu \mathrm{m}$ and for $W_{\mathrm{f}}$ at $15 \mu \mathrm{m}$. As a result, the total energy $\mathrm{W}$ reaches its maximum at a notch depth of $15 \mu \mathrm{m}$ and exceeds the values of the samples with unnotched z-pins by about $20 \%$. If a 
quasi-isotropic laminate structure is considered, the enhancements of the energy values are more pronounced and also have their maximum at a notch depth of $15 \mu \mathrm{m}$, irrespective of whether the elastic component, the frictional component, or the total energy is considered. The rise amounts to approximately $74 \%$ compared to the unnotched z-pins with the same laminate structure.

\subsection{Z-Pin Stiffness}

To determine the effect of notching on the measured axial stiffness of the z-pins introduced into a UD and QI laminate, the load-displacement relationships were used for calculating the values. The results are summarized in Table 2 for the various notch designs in unidirectional and quasi-isotropic laminates.

Table 2. Average stiffness and corresponding standard deviation values evaluated for different circumferentially notched z-pins inserted in unidirectional and quasi-isotropic laminates. The percentage of variation in stiffness in comparison to unnotched z-pins is also reported.

\begin{tabular}{clclc}
\hline Notch Design & $\mathrm{c}[\mathrm{kN} / \mathrm{mm}]$ & $\Delta \mathrm{c}[\%]$ & $\mathrm{c}[\mathrm{kN} / \mathbf{m m}]$ & $\Delta \mathrm{c}[\%]$ \\
\hline & \multicolumn{2}{l}{ Unidirectional } & \multicolumn{3}{l}{ Quasi-Isotropic } \\
\hline Unnotched & $1.06 \pm 0.11$ & - & $0.97 \pm 0.14$ & - \\
Rectangular & $1.13 \pm 0.05$ & +7 & $1.20 \pm 0.12$ & +24 \\
Triangular & $1.10 \pm 0.16$ & +4 & $1.17 \pm 0.08$ & +20 \\
Sinusoidal & $1.18 \pm 0.01$ & +11 & $1.12 \pm 0.08$ & +16 \\
Circular & $1.23 \pm 0.10$ & +16 & $1.17 \pm 0.20$ & +20 \\
\hline
\end{tabular}

The results show that the measured stiffness $c$ in a unidirectional laminate structure is slightly increased by the introduction of notches. The improvements range from $4 \%$ to $16 \%$, with the highest values being obtained by samples with circular notch designs. For QI laminates, the stiffness increase is higher compared to UD laminates, ranging between $16 \%$ and $24 \%$. The values observed consequently indicate an enlargement of the measured stiffness of the z-pins, independent of the notch design and laminate structure. The mechanisms responsible for the reported effects are not yet fully understood. It was expected that the insertion of the notches would cause cutting of fibers of the pin and result in reduced stiffness of the pins. The calculated stiffness data presented in the table are combined stiffness, which result from a proportion of the z-pins and a proportion of the laminate surrounding the pin. Likewise, fibers and matrix material of the laminate are pushed into the notches during the manufacturing process, contributing to the overall stiffness. The higher stiffness of the samples with quasi-isotropic laminate structures may result from the higher amount of entwining fibers of the laminate around the pins-also placed in the notches-compared to unidirectional laminates. With unidirectional laminates, only a limited area of the notches are filled with fibers of the laminate which contribute to the overall stiffness. From the studies of Wang et al. [38] on the performance of twisted composite z-pins, it is known that twisting of the fibers results in a significant reduction of the stiffness properties of the z-pins. The higher the number of turns of the fiber bundles, the larger the loss of stiffness. However, the maximum debonding pullout force could be improved by up to $19.4 \%$ for twisted pins in comparison to untwisted pins, due to the higher interlocking effects caused by the formation of helical grooves on pin surface due to fiber twisting (form closure). As already described by Hoffmann et al. [41], high stiffness of the inserted z-pins is crucial for an effective absorption of the applied loads under Mode-I crack-opening conditions and for a significant prevention of crack growth resulting from an enhancement of the elastic part of the pullout energy. Similar to the twisted z-pins, the results of the notched pins show improvements of the maximum debonding forces under pullout conditions, caused by the higher interlocking between pins and laminate. With a notch depth higher than $25 \mu \mathrm{m}$ using rectangular notch design in combination with an unidirectional laminate structure, we can observe that the calculated stiffness showed no clear trend, but increases of 3\% to $16 \%$ can be achieved. Results of the investigations performed on notched z-pins with different notch designs and 
a constant notch depth of $20 \mu \mathrm{m}$ follow the findings described by Hoffmann et al. [41]. The increases in the stiffness calculated for unidirectional laminate structures correspond with their results for the same laminate structure.

\section{Conclusions}

The positive effect of improved interlocking between z-pins and the surrounding laminate on the bridging mechanisms under crack-opening loads has already been shown in previous experimental investigations $[33,38,41]$. In continuation, experimental studies were conducted to determine the impact of the notch design on the resulting pullout properties of circumferentially notched z-pins. From the presented experimental investigations, the following conclusions can be drawn:

- By introducing notches at the z-pin surface, the maximum values of the characteristic pullout parameters - maximum debonding force $\mathrm{P}_{\mathrm{d}}$ and maximum frictional force $\mathrm{P}_{\mathrm{f}}$ - can be significantly increased compared to those of unnotched pins, regardless of notch design and laminate structure. The increases for UD laminate structures are lower than for QI laminates.

- The resulting pullout energies follow the values found for the characteristic pullout forces. Therefore, the gains in pullout energy $W$ for QI laminates are higher for all notch designs than for UD laminates, compared to the unnotched pins.

- For unidirectional laminates, no substantial variation of the resulting total pullout energy for the different notch designs can be determined. In contrast, the investigations on QI laminates show that the highest increases in total pullout energy of up to $69 \%$ can be achieved for sinusoidal notch designs.

- Examining the dependence of the pullout forces and energies on the notch depth with a circular notch design at constant notch width and distance, it can be seen that the maximum values occur at a notch depth of approximately $15 \mu \mathrm{m}$, regardless of the laminate structure considered.

- Notched pins show a significant increase in the elastic part of the pullout energy $W_{\mathrm{e}}$, especially in a QI laminate structure. Therefore, independent from the notch design, notched z-pins can effectively stop crack growth under mode-I loading by hindering pin separation, and therefore prevent reaching the frictional pullout phase, unless it is with much higher energy values.

- The application of circumferential notches has no negative impact on the measured stiffness of the pins in the laminate during pullout loading. Instead, slightly higher values can be found for all notch designs, whereby the values for QI laminate structures are higher than the values for UD laminate structures.

The treatment of the pins by ultra-short laser pulses causes a surface roughness in the root of the notches, which depends on the processing parameters (e.g., depth of ablation per processing step, speed of processing, laser power, and further). Additional investigations should clarify whether there is a dependency of the surface roughness in the root of the notches on the resulting pullout properties and which parameters must be selected to find an optimal surface roughness for the specific notch geometry. Further studies are necessary to examine the effects of the improved bridging mechanisms on the resulting fracture-mechanical properties, especially for Mode-II crack-opening loads. Particularly in the case of Mode-II crack-opening loading, which results primarily in shear failure of the z-pins, the reduced cross-sections can potentially result in a reduction of delamination toughness. The impact of a microstructuring of the z-pin surfaces on the in-plane properties must also be investigated in order to quantify any negative effects. Due to the additional stress concentrations in the area of the notches that are caused by the geometrical cross-over points, the resulting dynamic properties could also be strongly affected and should therefore be investigated.

Author Contributions: Conceptualization, A.K. and G.S.; methodology, A.K. and G.S.; validation, G.S.; formal analysis, A.K.; investigation, A.K.; resources, G.S.; data curation, A.K.; writing-original draft preparation, A.K.; writing-review and editing, A.K.; visualization, A.K.; supervision, G.S.; project administration, A.K. and G.S.; funding acquisition, G.S. All authors have read and agreed to the published version of the manuscript. 
Funding: The studies were conducted as part of a research project (project number: 398803737) funded by the German Science Foundation (DFG). The authors sincerely thank the DFG for this support. Additionally, the authors thank the Cytec Engineered Materials $\mathrm{GmbH}$ for supporting the studies by providing the prepreg material used.

Acknowledgments: We acknowledge financial support by Deutsche Forschungsgemeinschaft and Universität Rostock/Universitätsmedizin Rostock within the funding programme (project number: 325496636) Open Access Publishing.

Conflicts of Interest: The authors declare no conflict of interest. The funders had no role in the design of the study; in the collection, analyses, or interpretation of data; in the writing of the manuscript, or in the decision to publish the results.

\section{References}

1. Kinloch, A.J.; Young, R.J. Fracture Behaviour of Polymers; Applied Science Publishers and Sole distributor in the USA and Canada; Elsevier Science Pub. Co.: London, UK; New York, NY, USA, 1983.

2. Yee, A.F.; Pearson, R.A. Toughening mechanisms in elastomer-modified epoxies. J. Mater. Sci. 1986, 21, 2462-2474. [CrossRef]

3. Mouritz, A.P.; Bannister, M.K.; Falzon, P.J.; Leong, K.H. Review of applications for advanced three-dimensional fibre textile composites. Compos. Part A Appl. Sci. Manuf. 1999, 30, 1445-1461. [CrossRef]

4. Tong, L.; Mouritz, A.P.; Bannister, M.K. 3D Fibre Reinforced Polymer Composites, 1st ed.; Elsevier: Boston, MA, USA, 2002.

5. Huang, T.; Wang, Y.; Wang, G. Review of the Mechanical Properties of a 3D Woven Composite and Its Applications. Polym. Plast. Technol. Eng. 2018, 57, 740-756. [CrossRef]

6. Bilisik, K. Three-dimensional braiding for composites: A review. Text. Res. J. 2013, 83, 1414-1436. [CrossRef]

7. Bogdanovich, A. An overview of three-dimensional braiding technologies. In Advances in Braiding Technology; Kyosev, Y., Ed.; Woodhead Publishing Series in Textiles; Woodhead Publishing: Cambridge, UK, 2016; pp. 3-78.

8. Dransfield, K.; Baillie, C.; Mai, Y.W. Improving the delamination resistance of CFRP by stitching-A review. Compos. Sci. Technol. 1994, 50, 305-317. [CrossRef]

9. Mouritz, A.; Leong, K.; Herszberg, I. A review of the effect of stitching on the in-plane mechanical properties of fibre-reinforced polymer composites. Compos. Part A Appl. Sci. Manuf. 1997, 28, 979-991. [CrossRef]

10. Dell'Anno, G.; Cartié, D.D.; Partridge, I.K.; Rezai, A. Exploring mechanical property balance in tufted carbon fabric/epoxy composites. Compos. Part A Appl. Sci. Manuf. 2007, 38, 2366-2373. [CrossRef]

11. Gnaba, I.; Legrand, X.; Wang, P.; Soulat, D. Through-the-thickness reinforcement for composite structures: A review. J. Ind. Text. 2019, 49, 71-96. [CrossRef]

12. Kusaka, T.; Watanabe, K.; Hojo, M.; Fukuoka, T.; Ishibashi, M. Fracture behaviour and toughening mechanism in Zanchor reinforced composites under mode I loading. Eng. Fract. Mech. 2012, 96, 433-446. [CrossRef]

13. Itabashi, T.; Iwahori, Y.; Watanabe, N.; Ishibashi, M.; Takeda, F.; Ishikawa, T. Mode I interlaminar fracture mechanical properties of the CFRP laminates enhanced by Zanchor technology. In Proceedings of the 16th International Conference on Composite Materials, Kyoto, Japan, 8-13 July 2007; pp. 8-13.

14. Mouritz, A.P. Review of z-pinned composite laminates. Compos. Part A Appl. Sci. Manuf. 2007, 38, $2383-2397$. [CrossRef]

15. Freitas, G.; Magee, C.; Dardzinski, P.; Fusco, T. Fiber insertion process for improved damage tolerance in aircraft laminates. J. Adv. Mater. 1994, 25, 36-43.

16. Liu, H.Y.; Takeda, N.; Yan, W.; Hamada, H.; Gu, B.; Ogihara, S.; Dai, S.C.; Nakai, A.; Mai, Y.W. Z-pinning reinforcement and its bridging law. In Proceedings of the Asian-Australian Conference on Composite Materials, Japan, 18-21 November 2003; pp. 389-393.

17. Cartié, D.D.R.; Troulis, M.; Partridge, I.K. Delamination of Z-pinned carbon fibre reinforced laminates. Compos. Sci. Technol. 2006, 66, 855-861. [CrossRef]

18. Cartié, D.D.R.; Laffaille, J.M.; Partridge, I.K.; Brunner, A.J. Fatigue delamination behaviour of unidirectional carbon fibre/epoxy laminates reinforced by Z-Fiber ${ }^{\circledR}$ pinning. Eng. Fract. Mech. 2009, 76, 2834-2845. [CrossRef] 
19. Ranatunga, V.; Clay, S.B. Cohesive modeling of damage growth in z-pinned laminates under mode-I loading. J. Compos. Mater. 2013, 47, 3269-3283. [CrossRef]

20. Partridge, I.K.; Cartié, D.D.R. Delamination resistant laminates by Z-Fiber ${ }^{\circledR}$ pinning: Part I manufacture and fracture performance. Compos. Part A Appl. Sci. Manuf. 2005, 36, 55-64. [CrossRef]

21. Hoffmann, J.; Scharr, G. Mode I delamination fatigue resistance of unidirectional and quasi-isotropic composite laminates reinforced with rectangular z-pins. Compos. Part A Appl. Sci. Manuf. 2018, 115, 228-235. [CrossRef]

22. Yan, W.; Liu, H.Y.; Mai, Y.W. Mode II delamination toughness of z-pinned laminates. Compos. Sci. Technol. 2004, 64, 1937-1945. [CrossRef]

23. Cartié, D.D.R.; Cox, B.N.; Fleck, N.A. Mechanisms of crack bridging by composite and metallic rods. Compos. Part A Appl. Sci. Manuf. 2004, 35, 1325-1336. [CrossRef]

24. Allegri, G.; Yasaee, M.; Partridge, I.K.; Hallett, S.R. A novel model of delamination bridging via Z-pins in composite laminates. Int. J. Solids Struct. 2014, 51, 3314-3332. [CrossRef]

25. Zhang, B.; Allegri, G.; Yasaee, M.; Hallett, S.R. Micro-mechanical finite element analysis of Z-pins under mixed-mode loading. Compos. Part A Appl. Sci. Manuf. 2015, 78, 424-435. [CrossRef]

26. Rugg, K.L.; Cox, B.N.; Massabò, R. Mixed mode delamination of polymer composite laminates reinforced through the thickness by z-fibers. Compos. Part A Appl. Sci. Manuf. 2002, 33, 177-190. [CrossRef]

27. Zhang, X.; Hounslow, L.; Grassi, M. Improvement of low-velocity impact and compression-after-impact performance by z-fibre pinning. Compos. Sci. Technol. 2006, 66, 2785-2794. [CrossRef]

28. Knaupp, M.; Baudach, F.; Franck, J.; Scharr, G. Impact and post-impact properties of cfrp laminates reinforced with rectangular z-pins. Compos. Sci. Technol. 2013, 87, 218-223. [CrossRef]

29. Partridge, I.K.; Cartié, D.D.R.; Bonnington, T. Manufacture and performance of z-pinned composites. In Advanced Polymeric Materials: Structure Property Relationships; Shonaike, G.O., Advani, S.G., Eds.; CRC Press: Boca Raton, FL, USA, 2003; pp. 114-153.

30. Massabò, R.; Cox, B.N. Unusual Characteristics of Mixed-Mode Delamination Fracture in the Presence of Large-Scale Bridging. Mech. Compos. Mater. Struct. 2001, 8, 61-80. [CrossRef]

31. Cartié, D.D.R. Effect of $z$-Fibres ${ }^{\mathrm{TM}}$ on the Delamination Behaviour of Carbon-Fibre/Epoxy Laminates. Ph.D. Thesis, Cranfield University, Cranfield, UK, 2000.

32. Dai, S.C.; Yan, W.; Liu, H.Y.; Mai, Y.W. Experimental study on z-pin bridging law by pullout test. Compos. Sci. Technol. 2004, 64, 2451-2457. [CrossRef]

33. Knopp, A.; Scharr, G. Effect of z-pin surface treatment on delamination and debonding properties of z-pinned composite laminates. J. Mater. Sci. 2014, 49, 1674-1683. [CrossRef]

34. Knopp, A.; Scharr, G. X-ray photo-electron spectroscopic studies of cryogenic and plasma surface-treated z-pins. J. Compos. Mater. 2017, 51, 1155-1166. [CrossRef]

35. Knopp, A.; Scharr, G. Improvement of pullout performance of surface modified z-pins in three-dimensional carbon fibre reinforced composite laminates. In Proceedings of the 19th World Congress on Materials Science and Engineering, Vienna, Austria, 24 June 2019.

36. Wang, X.X.; Chen, L.; Jiao, Y.N.; Li, J.L. Preparation of carbon fiber powder-coated Z-pins and experimental study on the mode I delamination toughening properties. Polym. Compos. 2016, 37, 3508-3515. [CrossRef]

37. Vazquez, J.T.; Castanié, B.; Barrau, J.J.; Swiergiel, N. Multi-level analysis of low-cost Z-pinned composite joints: Part 1: Single Z-pin behaviour. Compos. Part A Appl. Sci. Manuf. 2011, 42, 2070-2081. [CrossRef]

38. Wang, X.X.; Chen, L.; Jiao, Y.N.; Li, J.L. Experimental study on interfacial adhesive properties between twisted Z-pin and laminates. J. Solid Rocket Technol. 2014, 37, 856-862.

39. Zhang, X.; Li, Y.; Chu, Q.; Xiao, J. Experimental study on the performance of twisted fiber reinforced composite z-pin. In Proceedings of the 21th International Conference on Composite Materials, Xi'an, China, 20-25 August 2017.

40. Virakthi, A.; Kwon, S.; Lee, S.W.; Robeson, M.E. Delamination resistance of composite laminated structures reinforced with angled, threaded, and anchored Z-pins. J. Compos. Mater. 2019, 53, 1507-1519. [CrossRef] 
41. Hoffmann, J.; Sabban, J.; Scharr, G. Pullout performance of circumferentially notched z-pins in carbon fiber reinforced laminates. Compos. Part A Appl. Sci. Manuf. 2018, 110, 197-202. [CrossRef]

42. Freitas, G.; Magee, C.; Boyce, J.; Bott, R. Service tough composite structures using z-fibers process. In Proceedings of the 9th DoD/NASA/FAA Conference on Fibrous Composites, Lake Tahoe, NV, USA, 4-7 November 1991; pp. 2657-2665.

(C) 2020 by the authors. Licensee MDPI, Basel, Switzerland. This article is an open access article distributed under the terms and conditions of the Creative Commons Attribution (CC BY) license (http:/ / creativecommons.org/licenses/by/4.0/). 